\title{
INVESTIGATION OF THE BENEFITS OF PLASMA DEPOSITION FOR THE ADDITIVE LAYER MANUFACTURE OF $\mathrm{Ti}-6 \mathrm{Al}-4 \mathrm{~V}$
}

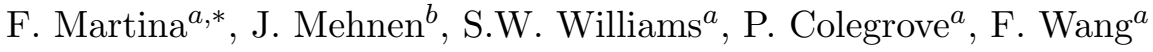

${ }^{a}$ Welding Engineering and Laser Processing Centre (WELPC), Building 46, Cranfield University, MK43 0AL, United Kingdom

${ }^{b}$ Manufacturing Department, Building 50, Cranfield University, MK43 0AL, United Kingdom

* Corresponding author. Tel.: +44 (0) 1234750111 ext 5055; Fax: +44 (0) 1234 754717; Email address: f.martina@cranfield.ac.uk

\begin{abstract}
With increasing emphasis on sustainability, Additive Layer Manufacturing (ALM) offers significant advantages in terms of reduced buy-to-fly ratios and improved design flexibility. Plasma Wire Deposition is a novel ALM technique in which plasma welding and wire feeding are combined. In the present work, a working envelope for the process using $\mathrm{Ti}-6 \mathrm{Al}-4 \mathrm{~V}$ was developed, and regression models were calculated for Total Wall Width, Effective Wall Width and Layer Height. The Plasma Wire Deposition process is able to produce straight walls of widths up to $17.4 \mathrm{~mm}$ giving a

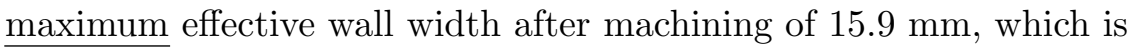
considerably wider than competing processes. In addition, for $\mathrm{Ti}-6 \mathrm{Al}-4 \mathrm{~V}$ the deposition efficiency averages $93 \%$ and the maximum deposition rate is $1.8 \mathrm{~kg} / \mathrm{h}$. Coarse columnar grains of $\beta$ phase grew from the base during deposition, which transformed into a Widmanstätten structure of $\alpha$
\end{abstract}


lamellae on cooling. Bands were identified in the deposits, which had a repetitive basket-weave microstructure that varied in size. The strength measured by micro-indentation hardness of $387 \mathrm{HV}$ on average is as much as $12 \%$ higher than the substrate. These preliminary results indicate that Plasma Wire Deposition is likely to be a suitable process for the ALM of large aerospace components.

\section{Keywords}

Ti-6Al-4V, Additive layer manufacturing, shaped metal deposition, plasma welding, plasma wire deposition, D-optimal design

\section{Nomenclature}

$\begin{array}{ll}\text { ALM } & \text { Additive Layer Manufacturing } \\ \text { CMT } & \text { Cold Metal Transfer } \\ \text { DE } & \text { Deposition Efficiency } \\ \text { EWW } & \text { Effective Wall Width } \\ \text { I } & \text { Current } \\ \text { GMAW } & \text { Gas Metal Arc Welding } \\ \text { GTAW } & \text { Gas Tungsten Arc Welding } \\ \text { LH } & \text { Layer Height } \\ \text { PWD } & \text { Plasma Wire Deposition } \\ \text { SW } & \text { Surface Waviness } \\ \text { TS } & \text { Travel Speed } \\ \text { TWW } & \text { Total Wall Width } \\ \text { WFS } & \text { Wire Feed Speed }\end{array}$

\section{Introduction}

According to Baufeld et al. (2010), Additive Layer Manufacturing (ALM) is a technology that enables the fabrication of complex, near net shape components by deposition of many consecutive layers of a specific material. The first applications of ALM, such as those described in Akula and 
Karunakaran (2006), involved rapid prototyping of plastic components and facilitated shorter product development times and product life cycles. Gradually, research efforts moved towards metal deposition, especially for materials which are either difficult to machine or are expensive to buy, where waste needs to be minimised. Metal ALM techniques differ depending upon the heat source and the form of the fed material. Kruth et al. (2007) provided an extensive review of Selective Laser Melting, in which a powder bed is scanned by a laser. Wang et al. (2006) investigated the Direct Laser Fabrication of Ti-6Al-4V supplying both blown powder and fed wire, in the attempt to produce well bonded composites. An alternative to Select Laser Melting is Electron Beam Melting: Murr et al. (2010) used this process to additive layer manufacture Ti-6Al-4V cellular foams. Aiming at increased deposition rates, arc-based welding techniques have been used for ALM purposes. Baufeld et al. (2010) succeeded in producing $\mathrm{Ti}-6 \mathrm{Al}-4 \mathrm{~V}$ tubular components in high purity argon atmosphere by using Gas Tungsten Arc Welding (GTAW). In Sequeira Almeida and Williams (2010) the Cold Metal Transfer (CMT) Gas Metal Arc Welding (GMAW) was used to deposit Ti-6Al-4V out-of-chamber. This work included the development of a process model which enabled the selection of the most appropriate process parameters for a given wall geometry. Although some work on the combination of plasma welding process and powder feeding is available (Xiong, 2008; Zhang et al., 2003), to the best knowledge of the authors nothing has been published on the combination of plasma welding and wire feeding.

All the powder-bed based techniques require support structures when non-vertical parts are built. While laser-based techniques produce a higher dimensional accuracy, there are some specific issues. First, the deposition 
rates are relatively low, with values typically being $9-120 \mathrm{~g} / \mathrm{h}$ as reported in Zhang et al. (2003). Second, during its scanning path the laser spot could influence an area which is larger than the laser bead itself, thus generating a phenomenon called balling, which is described in Tolochko et al. (2004). Finally, with the currently available equipment, parts greater than $300 \times 350 \times 300 \mathrm{~mm}^{3}$ are difficult to build with powder bed technology. Wire-based techniques overcome many of the problems of powder-based techniques for large structures. Their deposition rates can be more than ten times higher, and there is almost no limitation regarding the size of the part which can be built, provided the manipulator is sufficiently large and gas shielding local to the torch can be implemented. There are fewer contamination issues during the process, as all the fed wire goes in the molten pool. Many of the powder based techniques use powder recycling which can introduce contamination.

While previous work in Sequeira Almeida and Williams (2010) has demonstrated the production of $1000 \times 200 \times 4 \mathrm{~mm}^{3}$ titanium walls using the GMAW processes, the subject of the present paper is the investigation and characterisation of Plasma Wire Deposition (PWD). As described in Messler (1999), non-transferred plasma arc welding is a process in which an arc is created between between a non-consumable tungsten electrode (cathode) and a copper anode within the torch. An inert gas (usually argon) is forced through the orifice formed between the cathode and anode, thus constricting the arc. This leads to higher energy density, increased arc stability and reduced contamination when compared with competing processes such as GTAW deposition. Weman (2003) reported that higher travel speeds and quality can be achieved when welding with this process, so it stands to reason that similar advantages can be achieved 
with ALM. Moreover, the production of a model capable of predicting the main geometric features of the deposit is attempted.

\section{Methodology}

\subsection{Experimental setup}

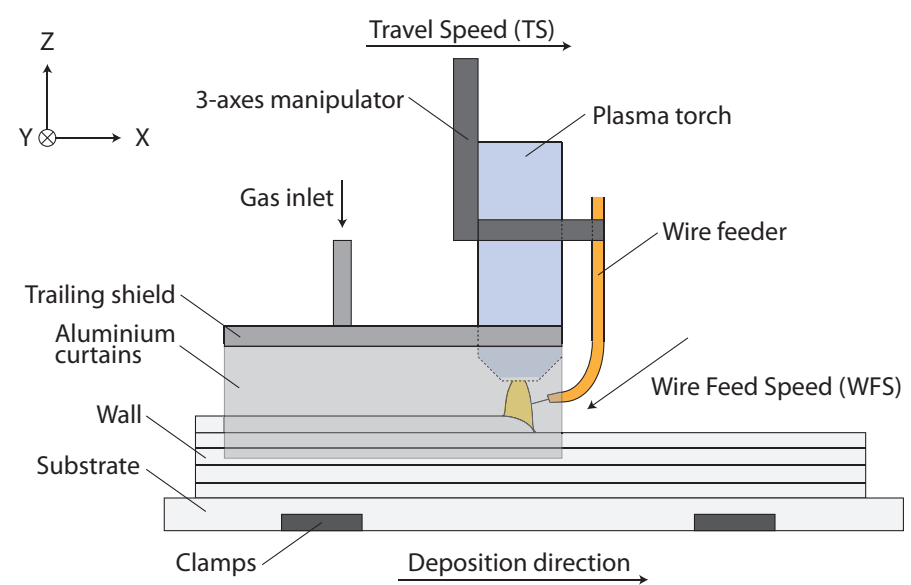

Figure 1: Schematic representation of Plasma Wire Deposition experimental equipment.

The equipment used for PWD is shown in Fig. 1 and consists of: Liburdi Engineering PW-400C Plasma Torch, equipped with a $100 \mathrm{~mm}$ long trailing shield; and a Liburdi Pulseweld LP4000-VC Power Source.

Pureshield Argon Gas was used for both the plasma and the shielding gas. The torch standoff was $7 \mathrm{~mm}$ (enough to ensure no crash could occur) and the electrode set back was $5 \mathrm{~mm}$ (suggested by torch manufacturer). These were not adjusted during the experiments. The wire diameter was $1.2 \mathrm{~mm}$ and the wire was fed from the front of the welding pool, as shown in Fig. 1. The wire chemical composition is shown in Table 1. The phases of the deposition operation and the corresponding gas flow-rates for the plasma gas, shield gas and trailing shield are shown in Table 2 . 


\subsection{Preliminary experiments for determining process window}

Due to the novelty of using PWD for ALM, a set of 34 preliminary single layer (bead on plate) experiments provided the necessary information for understanding the general behaviour of the process and determining the limitations of the process parameters. Deposition may be unfeasible due to physical limits or impractical parameters combinations. The experimental set up was the same as that described in Section 2.1. While two parameters were kept constant, the other was varied in fixed steps till an unfeasible combination was found on the basis of visual assessment of the deposited layer.

\subsection{Experiments for developing the process model}

The walls were made of 14 layers and were $140 \mathrm{~mm}$ long. Layer deposition always started from the same end. Before starting each wall, the plates were cleaned with a stainless steel wire brush and acetone, to eliminate surface contamination. Three ALM straight walls were built by PWD on Ti-6Al-4V plates measuring $200 \times 100 \times 7 \mathrm{~mm}^{3}$. The part was allowed to cool down to $100^{\circ} \mathrm{C}$ before depositing a new layer for consistent part geometry. Subsequent work has shown that the temperature of the substrate affects the droplet surface tension, which in-turn effects the deposit geometry.

$\underline{\text { Having established the process constraints, a D-Optimal design method }}$ (Montgomery, 2005) was chosen for the experiment. Optimal designs are computer-generated and are particularly suitable when the experimental

Table 1: Chemical composition of $1.2 \mathrm{~mm}$ Ti-6Al-4V wire.

\begin{tabular}{ccccccccccc}
\hline $\mathrm{Ti}$ & $\mathrm{Al}$ & $\mathrm{V}$ & $\mathrm{Fe}$ & $\mathrm{O}$ & $\mathrm{C}$ & $\mathrm{N}$ & $\mathrm{H}$ & $\mathrm{TOE}$ & $\mathrm{Y}$ & Others \\
\hline 89.397 & 6.14 & 3.96 & 0.18 & 0.14 & 0.02 & 0.011 & 0.001 & $<0.1$ & $<0.001$ & $<0.05$ \\
\hline
\end{tabular}


Table 2: Gas flow rates used for the different deposition stages.

\begin{tabular}{lccccc}
\hline & Pre Purge & Ignition & Deposition & Slope Down & Post Purge \\
\hline Plasma orifice gas flow rate [l/min] & 1.5 & 1.5 & 1.5 & 1.5 & 1.5 \\
Shield gas flow rate [l/min] & 20 & 20 & 25 & 20 & 20 \\
Trailing shroud gas flow rate [1/min] & 12 & - & 30 & 30 & 30 \\
Duration [s] & 5 & - & $14-70^{a}$ & 5 & 20 \\
\hline
\end{tabular}

Duration $[\mathrm{s}]$

${ }^{a}$ Duration depended on travel speed

region is irregular, the model is nonstandard (i.e. the experimenter knows

beforehand some interactions will not be significant), and/or there are certain sample size requirements (i.e. a reduced number of runs must be

done). A design is D-Optimal if it "minimises the volume of the joint confidence region on the vector of regression coefficients" (Montgomery, 2005). In practice, the experimenter inputs the constraint equations and specifies any conditions related to unnecessary model terms and sample size. The software then runs an algorithm and returns the set of experiments that have the highest D-Optimal efficiency.

$\underline{\text { After the preliminary experiment and factors reduction, Wire Feed Speed }}$ (WFS) $\left[X_{1}\right]$, Travel Speed (TS) $\left[X_{2}\right]$ and Current (I) $\left[X_{3}\right]$ were selected as the factors for the model. WFS is the speed $[\mathrm{mm} / \mathrm{s}]$ at which wire is fed into the molten pool (Fig. 11); TS is the travel speed $[\mathrm{mm} / \mathrm{s}]$ of the manipulator (and consequently of the torch) along the $\mathrm{Y}$ axis; and I [A] influences the heat input.

The three responses used in the model were Total Wall Width, Effective Wall Width and Layer Height, which are described in the next section. As cubic behaviour was expected, three-factor third-order polynomial 
functions were fitted:

$$
\begin{aligned}
Y & =\beta_{0}+\sum_{i=1}^{3} \beta_{i} x_{i}+\sum_{i=1}^{3} \beta_{i i} x_{i}^{2}+\sum_{i=1}^{3} \beta_{i i i} x_{i}^{3}+\sum_{i<j}^{3} \beta_{i j} x_{i} x_{j} \\
& +\sum_{i \neq 1}^{3} \beta_{i i j} x_{i}^{2} x_{j}+\beta_{123} x_{1} x_{2} x_{3}
\end{aligned}
$$

where $Y$ is the predicted response, $\beta_{0}$ is the constant process effect, $\beta_{i}$ is the the linear effect of $X_{i}, \beta_{i i}$ are the quadratic effects of $X_{i}, \beta_{i i i}$ are the cubic effects of $X_{i}, \beta_{i j}$ are the interactions of first order, $\beta_{i i j}$ are the interactions of second order, and $\beta_{123}$ is the interaction of third order. Stat-Ease Design-Expert® 7.1 is a statistical software that creates and evaluates general factorial designs, fractional factorial designs, response surfaces, optimal designs, and it was used in the present research. The software indicated that 28 experiments were necessary to calculate the regression coefficients for the full model.

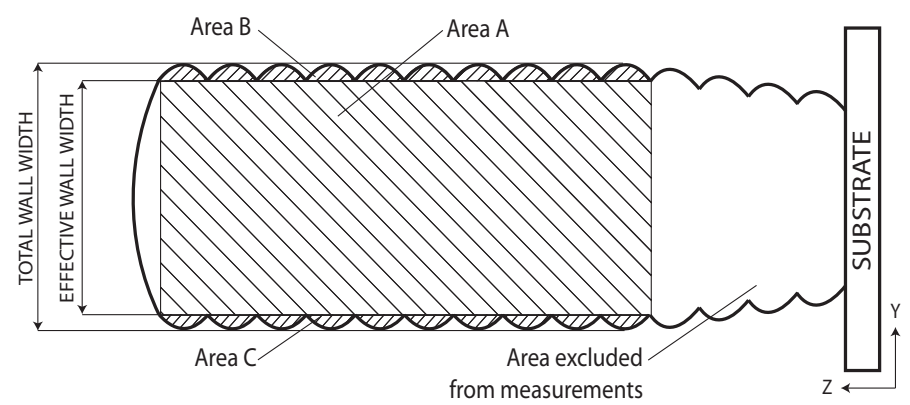

Figure 2: Schematic representation of a generic part cross-section. The Total Wall Width takes into account the entire width of the specimen, while the Effective Wall Width measures only what remains after having machined away the irregular side surfaces. Area A is the cross section enclosed by the Effective Wall Width, while areas B and C correspond to the cross sections that must be machined. 


\subsection{Measurements}

The deposited layer height was measured at $50 \mathrm{~mm}, 80 \mathrm{~mm}$ and $110 \mathrm{~mm}$ from the deposition starting point. The average was used to determine the height increment for deposition of the following layer. When calculating the average layer height, the first four layers were excluded because of the thermal effect of the base plate (Fig. 2). Transverse sections were taken, placed into resin, ground, polished and etched with hydrofluoric acid in order to take macro and micro images. The deposited walls have an $\underline{\text { irregular surface finish which makes a machining operation necessary to }}$ achieve plane side surfaces. The widths before and after machining are $\underline{\text { named the Total Wall Width (TWW) and the Effective Wall Width }}$ (EWW), respectively, the latter representing the width which is effectively usable. Both are shown in Fig. 2, Area A is the cross sectional area enclosed by the EWW; and areas B and C are the cross sectional areas of the material that would need to be removed by the machining operation. Adobe Photoshop ${ }^{\circledR}$ CS4 was used to measure both the widths and areas. In Adobe Photoshop, chromatic-based selection was used to highlight the various regions (A, B or $\mathrm{C}$ ). After defining the scale on the image, the $\underline{\text { software calculated their areas. }}$

Surface waviness was calculated as

$$
S W=(T W W-E W W) / 2
$$

and deposition efficiency as

$$
D E=A /(A+B+C)
$$

Both surface waviness and deposition efficiency indicate the amount of 
material that must be machined to achieve dimensional accuracy.

\section{Results and discussion}

\subsection{Working envelope}

The preliminary investigation on $\mathrm{Ti}-6 \mathrm{Al}-4 \mathrm{~V}$ deposition showed that the constraints on the parameters could be represented by the following equations:

$20 \leq$ Wire Feed Speed $\leq 100$

$2 \leq$ Travel Speed $\leq 10$

$120 \leq$ Current $\leq 300$

$160 \leq-5 \times$ Wire Feed Speed $+3 \times$ Current

$-520 \leq-8 \times$ Wire Feed Speed + Current 
$-200 \leq$ Wire Feed Speed - Current

$0 \leq-$ Wire Feed Speed $+20 \times$ Travel Speed

$0 \leq$ Wire Feed Speed $-5 \times$ Travel Speed

$-58 \leq-$ Wire Feed Speed $+6 \times$ Travel Speed

These are represented graphically in Fig. 3 in which they are related to the defects that can occur outside the working envelope. The low WFS and TS limits are due to the need for high deposition rates and therefore lower values were not considered. The WFS upper limit was due to a hardware limitation. The Current upper limit is related to the WFS upper limit, as $300 \mathrm{~A}$ is the current necessary to melt the amount of the WFS upper limit $(100 \mathrm{~mm} / \mathrm{s})$. On the one hand, when the heat input was insufficient, incomplete melting occurred (eq. (6), (7), (8); Fig. 3, images B3 and B4); on the other hand if the heat input was too high, the bead shape uniformity was badly affected (eq. (9); Fig. 3, images B1 and B2). Very high TS produced an exacerbated form of humping (eq. (5), (11); Fig. 3 , images A1 to A3); the high surface tension made the droplet solidify as soon as it touched the cold substrate; and the higher the WFS 

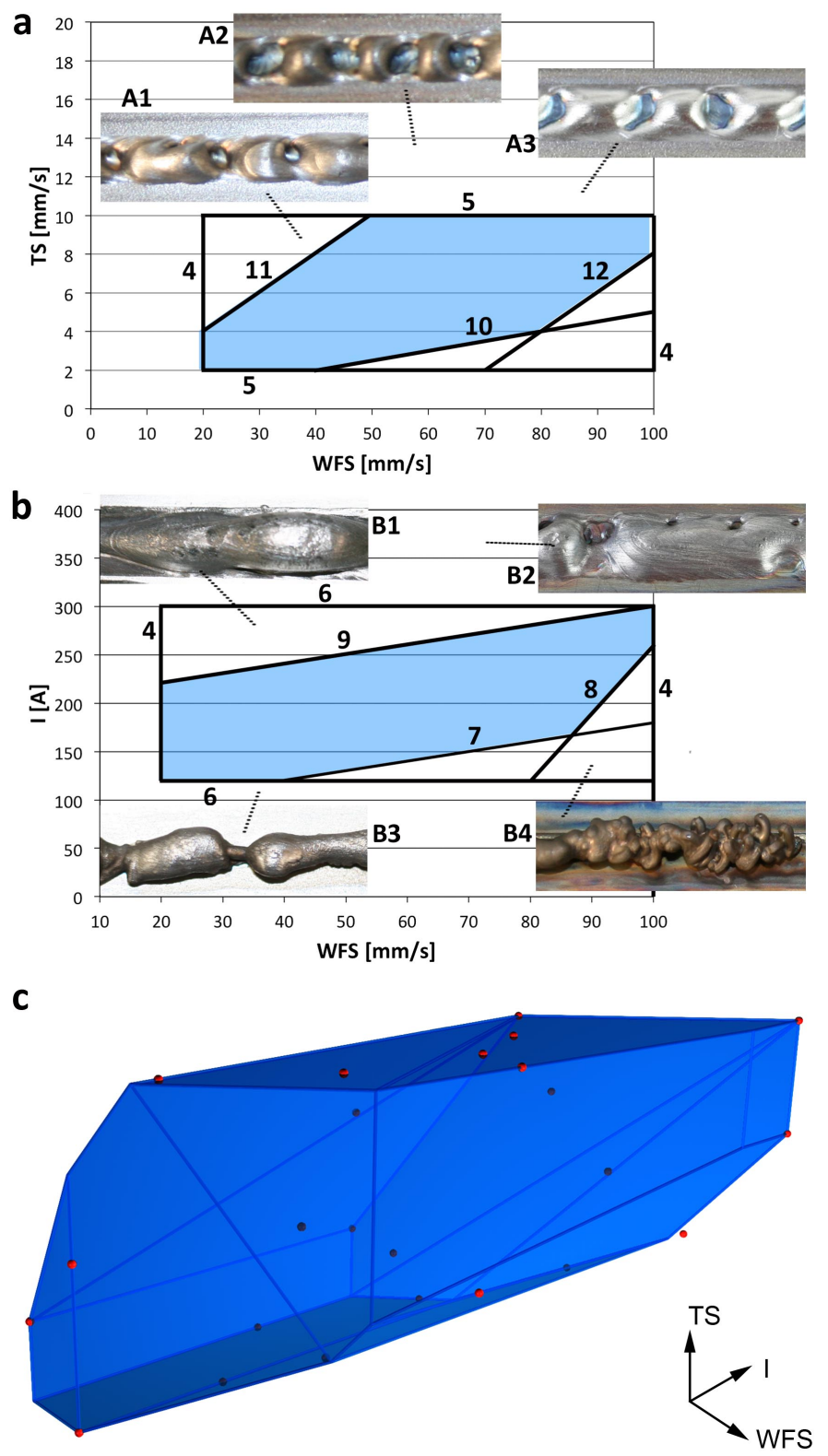

Figure 3: Working envelope for (a) WFS - TS and (b) WFS - Current plans. The numbers indicate the constraint each line refers to. (c) shows a $3 \mathrm{D}$ representation of the working envelope shaped by the constraints; the dots correspond to the 28 experiments necessary to calculate the regression coefficients for the models. 


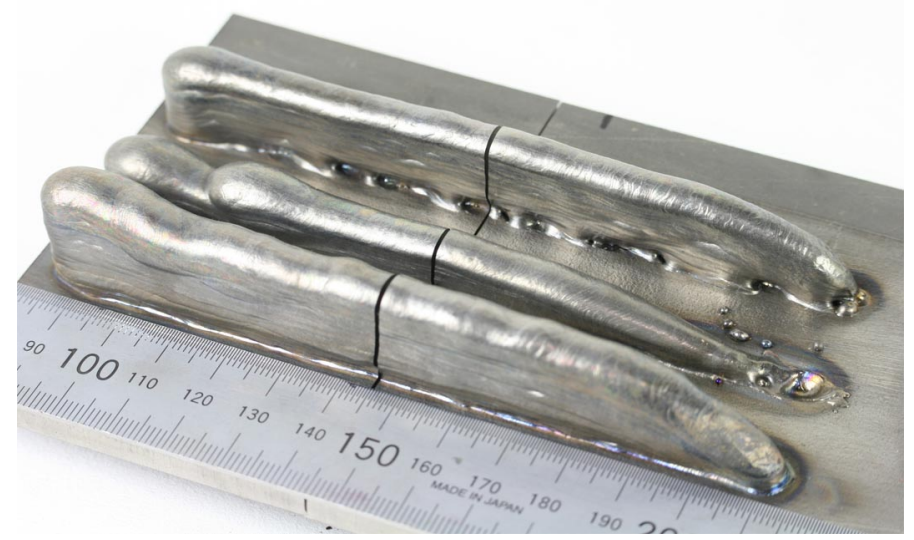

Figure 4: Examples of Ti-6Al-4V walls build by Plasma Wire Deposition (main ruler unit is $\mathrm{cm}$ ).

the larger the humps. This was the reason for the upper TS limit.

\subsection{Process capability}

A typical deposit is shown in Fig. 4, and a comparison against competing processes is shown in Fig. 5. The comparison data, for the GMAW and

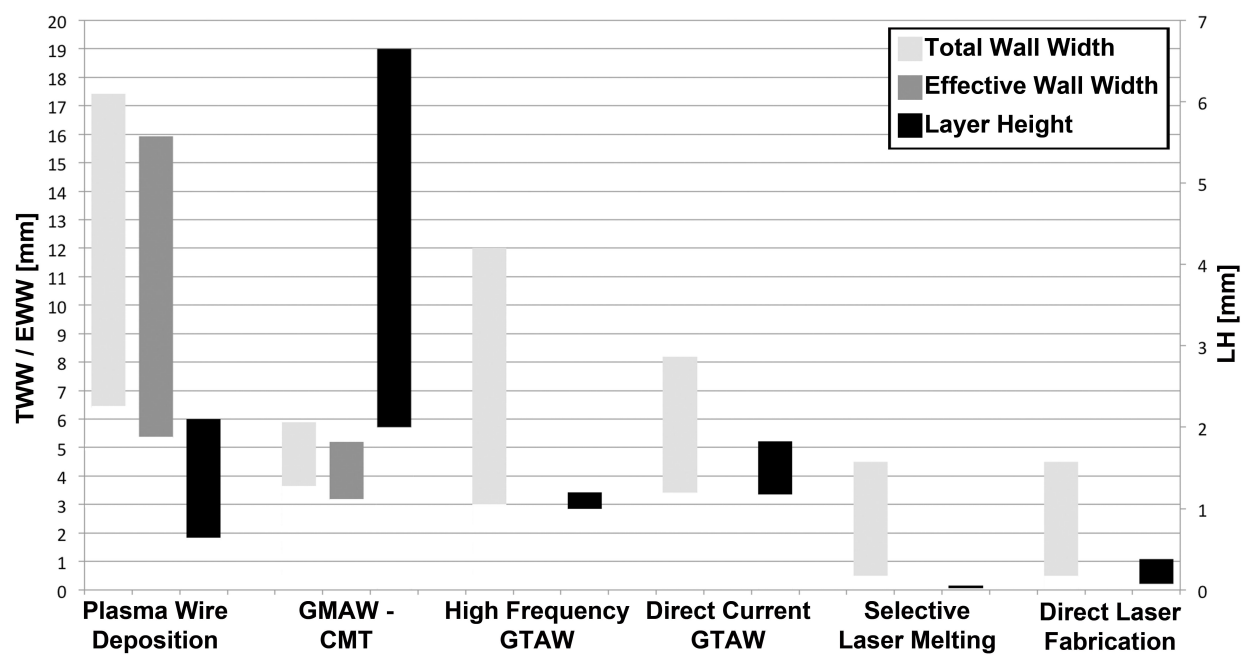

Figure 5: Comparison between PWD and other ALM processes in terms of Total Wall Width, Effective Wall Width and Layer Height. Effective Wall Width data are not available for High Frequency GTAW, Direct Current GTAW, Selective Laser Melting and Direct Laser Fabrication. 
GTAW processes considers only out-of-chamber manufacturing methods, and is taken from the work of Sequeira Almeida and Williams (2010), Eze (2009), Milewski et al. (1999) and Tolochko et al. (2004). Note that it was assumed that the wall width equalled the spot size for laser-based processes. The main advantage of the powder-bed laser deposition process is the small feature size capability. Finally it is interesting how the capabilities of PWD complement those of the GMAW-CMT process, with the latter producing thinner walls with a much greater layer height. Therefore, a combination of the two different processes could provide the capability to meet any geometric requirement.

The maximum deposition rate achieved using PWD was $1.8 \mathrm{~kg} / \mathrm{h}$; however, it was constrained by the $100 \mathrm{~mm} / \mathrm{s}$ limit of the wire feeder. The process showed the potential for further increasing the deposition rate, provided both the power and the WFS could be increased. The surface waviness ranged from $0.35 \mathrm{~mm}$ to $1.51 \mathrm{~mm}$, averaging $0.70 \mathrm{~mm}$. The average deposition efficiency was $93 \%$, and ranged from $85 \%$ to $98 \%$. These values were much higher than those from the GMAW-CMT process, whose average was around $80 \%$ (Sequeira Almeida and Williams, 2010). The time to deposit the 14 layers, considering deposition time only, ranged from 3 min $16 \mathrm{~s}$ to $16 \min 20 \mathrm{~s}$ and depended on the travel speed. The width of the first four layers was approximately $77 \%$ of the Total Wall Width, and $\underline{88 \% \text { of the Effective Wall Width of the subsequent layers. In practice, }}$ $\underline{\text { different parameters which produce a larger Effective Wall Width would be }}$ required for the first four layers. This was not studied within the scope of this work.

\subsection{Macrostructure}

Transverse cross sections of all the specimens revealed a common 
macrostructure, in which prior $\beta$ columnar grains grew from the base plate (Fig. 77) throughout the deposition process. In the ALM context, Baufeld et al. (2010), etc. described how Ti-6Al-4V solidifies in the body centred cubic $\beta$ phase, and then on cooling below $1000{ }^{\circ} \mathrm{C}$ partially transforms to the hexagonal closed packed $\alpha$ phase, surrounded by a matrix of $\beta$ phase. The grains were much larger than those in the base plate and are a consequence of epitaxial grain growth (that occurred during the deposition process) in which the favourably oriented grains grew instead of those what were not. The preferred direction is the one of the heat flow. In addition there were a series of bands in the microstructure which were convex at the bottom of the wall and were perpendicular to the wall toward the top. This feature will be discussed in the next section.

\subsection{Microstructure and Hardness}

Analysis of the deposited microstructure has shown a number of key features. Firstly, there is the upper region which consists of a fine $\underline{\text { microstructure as shown in Fig. 6. The microstructure within this region }}$ is relatively uniform and consists of very fine Widmanstätten and some needle-like $\alpha$ lamellae. The Widmanstätten microstructure consists of $\underline{\text { small } \alpha \text { colonies that nucleate into former } \beta \text { grains, which now appear as a }}$ matrix surrounding the $\alpha$ lamellae. $\alpha$ nucleation starts at the grain boundaries; when the nucleated $\alpha$ lamellae collide with each other and $\underline{\text { cannot grow further, additional nucleation occurs on the lamellae }}$ boundaries, causing new lamellae to grow perpendicular to the original ones, to minimise the elastic strain (Lütjering and Williams, 2007). While some authors (Gil et al., 2001; Lütjering and Williams, 2007) have interpreted the grid-looking microstructure such as the one found in the top region as martensite, others (Baufeld et al., 2009) have claimed that 


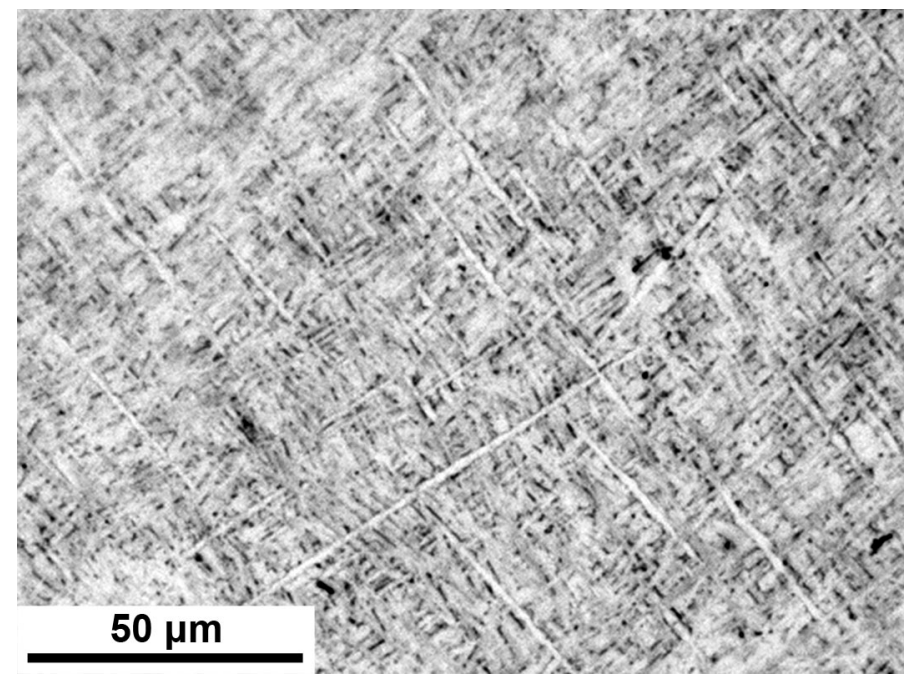

Figure 6: Fine lamellar structure typical of the top region of the deposits. Note some needle-like lamellae which suggests the presence of martensite.

such a microstructure is fine basket-weave. Irrespective of the interpretation, such a microstructure is typically produced by rapid cooling the material from above the $\beta$ transus temperature to room temperature, as described by Lütjering and Williams (2007), Gil et al. (2001), Filip et al. (2003), and Ahmed and Rack (1998). Underneath this region a series of bands is observed with one band being produced with each deposited layer. A generic band is indicated by the letter F in Fig. 7a. Analysis of the microstructure between two bands in Fig. 7, shows that there is an increase in $\alpha$ lamellae size (which was assessed visually) with increasing distance in the $Z$ direction, i.e. within two bands the size of the microstructure increases gradually towards the torch (see Fig. 7b to Fig. 7f). This kind of microstructure has also been observed by Kelly and Kampe (2004a), who claimed that the variation in microstructure size was due to compositional gradients or thermal effects.

An alternative explanation of the final microstructure is the consequence of multiple thermal cycles including: the one where the material was 

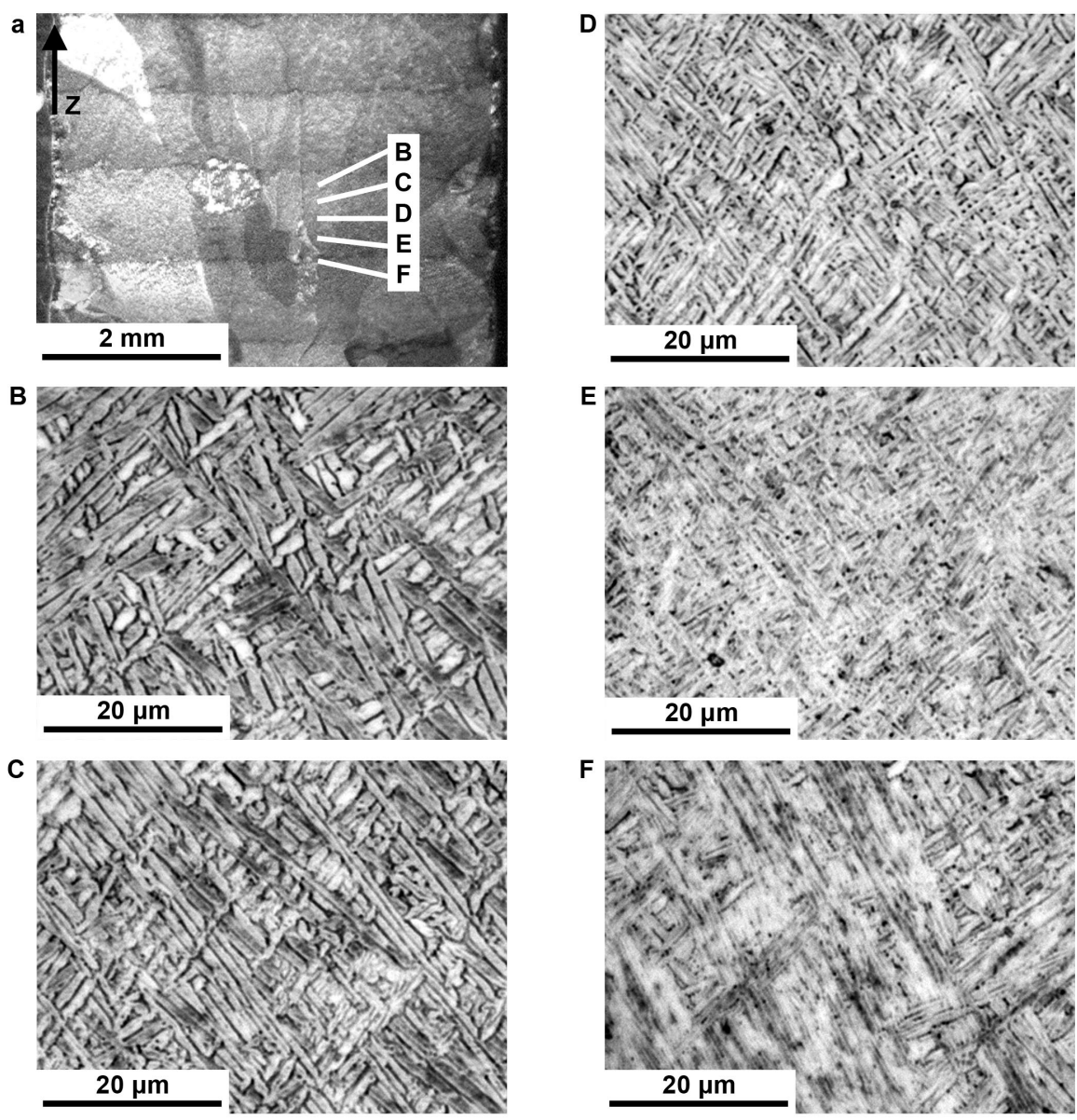

Figure 7: (a) macrostructure of a deposit; (B-F) microstructure of locations indicated in (a). The increase in Widmanstätten features size can be seen. 


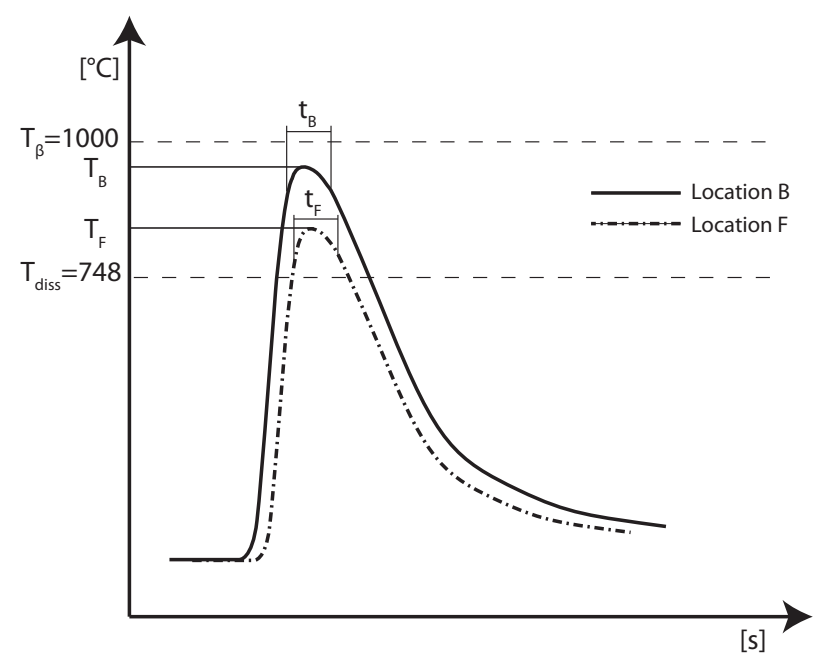

Figure 8: Suggested cooling curves for locations B and F in Fig. 7, $T_{B}$ and $T_{F}$ are the peak temperature achieved in these two points, while $t_{B}$ and $t_{F}$ are the times they are exposed to them for.

deposited, and the subsequent ones due to the succeeding layers. Analysis of the thermal history during ALM by Kelly and Kampe (2004b) and by an in-house thermal model of the process demonstrated little difference in the cooling rate in the top 4 to $5 \mathrm{~mm}$ of the deposit. Therefore provided that the temperature exceeds the $\beta$ transus temperature, there is unlikely to be any significant differences in the microstructure, and indeed a high $\underline{\text { cooling rate will produce a uniform martensitic (or fine Widmanstätten) }}$ microstructure.

Just below this region, i.e. the region identified by point B in in Fig. [7a, the peak temperature will be just below the $\beta$ transus temperature, so the microstructure will not fully transform to the $\beta$ phase. A typical thermal cycle is shown in Fig. 8, with peak temperature $T_{B}$. When held at this temperature for a time $t_{B}$, the $\beta$ phase transformation is avoided and there is sufficient temperature and time to induce coarsening of the $\alpha$-laths, a $\underline{\text { phenomenon also reported by Baufeld et al. (2009), the temperature being }}$ 
higher than the $\alpha$ dissolution temperature $\left(T_{\text {diss }}=748^{\circ} \mathrm{C}\right)$, which is the one "above which the equilibrium volume fraction of $\alpha$ begins to decrease" (Kelly and Kampe, 2004b). At a point further from the torch, i.e. at the point represented by point $\mathrm{F}$ in Fig. $7 \mathrm{~b}$ the peak temperature is not known, however it will be significantly lower than that obtained at point B. This is represented by the second thermal profile in Fig. 8 which has a peak temperature $T_{F}$ which is retained for a period of time $t_{F}$. This lower temperature is insufficient to induce coarsening, so the previous microstructure is largely retained, i.e. there is very little difference with the martensitic microstructure contained in the top region. Therefore the different microstructures that are observed within the bands are primarily a function of the peak temperature that the material achieves on the first thermal cycle where the peak temperature is less than the $\beta$ transus $\underline{\text { temperature; and are not due to differences in cooling rate as claimed by }}$ some authors. Note that the peak temperature in the subsequent thermal cycles is insufficient to cause significant microstructural changes.

Hardness measurements were done every $1.5 \mathrm{~mm}$ on four specimens along the centreline. While the average base plate hardness is $347 \mathrm{HV}$, the hardness of the four analysed specimens ranged from $342 \mathrm{HV}$ to $430 \mathrm{HV}$, averaging $387 \mathrm{HV}$. There was no particular trend in hardness values along the deposit. The standard deviation of the samples (20 HV) was similar to the base plate $(19 \mathrm{HV})$. The values indicated that some hardening of the material has occurred in the deposition process.

\subsection{Process Issues}

As stated in the methodology, it was necessary to wait until the material cooled down to $100{ }^{\circ} \mathrm{C}$, before depositing the next layer. The thermal conductivity of $\mathrm{Ti}-6 \mathrm{Al}-4 \mathrm{~V}$ is relatively poor $(7.2 \mathrm{~W} / \mathrm{mK})$, so the waiting 
time can be substantially larger than the actual deposition time. This problem was particularly acute with the small specimens investigated in this study. It is intended that the process will be implemented on large structures, where the time between successive layers will be long due to the size of the component, hence it is unlikely to be an issue in practice. Other solution strategies may involve depositing multiple components at once or in-process cooling.

The wall height was inconsistent; there was a distinct hump at the beginning and a depression towards the end, which is shown in Fig. 4. The depression at the end is likely to be due to the build-up of heat caused by the lack of heat sink in front of the torch. This could be addressed by reducing the current at the end of the travel. The likely cause of the hump at the beginning may be the thermal effect associated with the deposition on the cold base material. Both problems can be solved by changing the deposition strategy: instead of starting each layer form the same point, each layer could be started where the previous one finished. In this way, humping and sloping would be equally distributed at the two ends, compensating each other. This solution, which does not require any modification to the process parameters, has been successfully tested. In only 4 specimens (out of a total 32) a cavity in the longitudinal direction was observed (Fig. $9 \mathrm{a}$ and b). In these specimens, the cooling rate was sufficiently high to prevent the molten metal filling the cavity created by the plasma jet. In two of the specimens the cavity was only observed in the base material while in the other two the cavity extended through the deposit. These two specimens had the same deposition parameters, the second being a replication of the first, in the design of the experiment. Therefore the occurrence of the defect was to be expected in 
both of them. Cavity formation is undesirable in an industrial application, therefore parameters combinations that cause cavity formation should be excluded from the working envelope.

Oxidation represents a major issue in this phase of the process development. A number of samples showed surface discolouration after deposition (Fig. 9p). The colour may vary from yellowish to dark grey and was more prevalent as the deposit height increased due to the difficulty in adequately shielding the component. More effective shielding devices need to be developed for out-of-chamber deposition. Finally distortion was evident even on these small samples indicating that residual stresses in the deposited layers are likely to be significant and will need to be addressed.

\subsection{Statistical Analysis}

To determine the relationship between the measured response and the statistically significant variables, analysis of variance (ANOVA) was performed. This produced the following response models for the Total Wall Width (TWW in [mm]), Effective Wall Width (EWW in [mm]) and
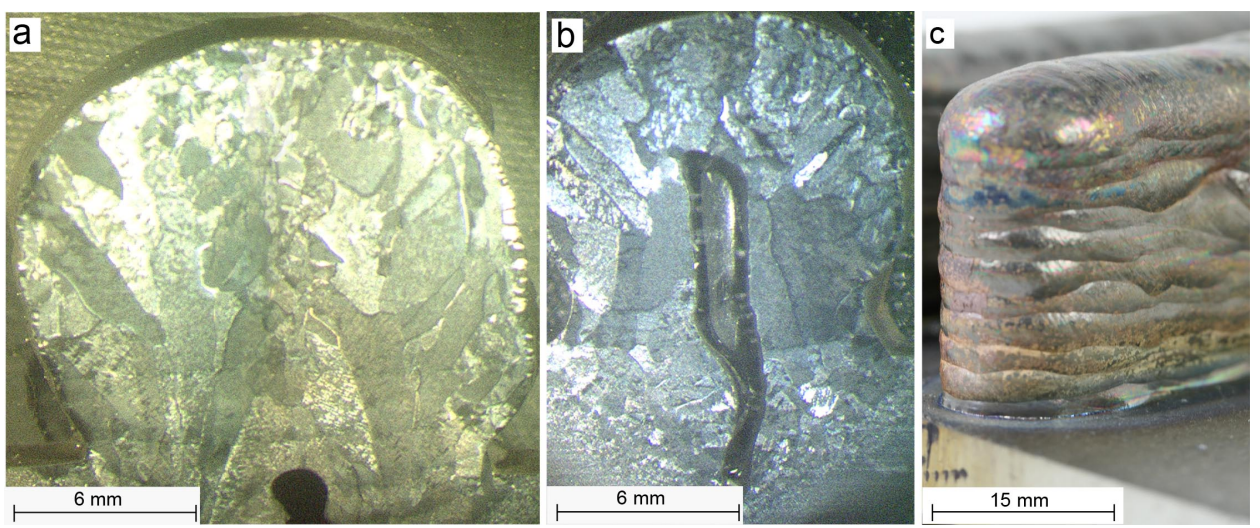

Figure 9: Issues include cavities and surface oxidation (c). Cavities were observed in 4 specimens: (a) cavity in the baseplate only and (b) extended through the deposit. 
the Layer Height ( $\mathrm{LH}$ in $[\mathrm{mm}])$ :

$$
\begin{aligned}
T W W & =6.88239-0.044619 \times W F S-2.24209 \times T S+0.11751 \\
& \times I+0.00111 \times W F S \times I-0.00332 \times T S \times I-0.00132 \\
& \times W F S^{2}+0.14513 \times T S^{2}-0.000316 \times I^{2} \\
E W W & =8.5012-2.27791 \times T S+0.073942 \times I+0.000906 \\
& \times W F S \times I-0.00329 \times T S \times I-0.00144 \times \\
& W F S^{2}+0.15051 \times T S^{2}-0.000179 \times I^{2} \\
& \\
& \\
L H= & 2.13394-0.075481 \times W F S-0.257 \times T S-0.022745 \\
I- & 0.0000725 \times I^{2}
\end{aligned}
$$

Even though cubic models were used, the analysis of variance indicated that none of the cubic terms were significant. Surprisingly, the linear term of WFS has statistical relevance in the TWW model but not in the EWW. Table 3 presents the coefficients of determination $\left(R^{2}\right)$ and adjusted- $R^{2}$ for the three models. Both $R^{2}$ coefficients, which according to Montgomery (2005) measure the proportion of the variability in the data that can be explained by the model, indicate that over $95 \%$ of the variability can be explained by the models, except for the LH response. The poorer value of $R^{2}$ for the LH could have been a consequence of the large variability in the wall height, which was observed along the sample. This could have affected the reliability of the regression analysis. In fact, in the case of the LH 
model the p-value for Lack of Fit is significant (0.0154). Montgomery (2005) explains that the p-value helps the decision maker to determine the significance of the data, and its threshold is usually 0.05; and Lack of Fit is the sum of squares of dropped factors. Provided that all and only the non-significant terms were excluded from the model, one can assume that the significant Lack of Fit is given by random errors in the data. Further experiments are necessary using longer walls, in which the steady state deposition is extended providing more accurate measurements.

Pred- $R^{2}$ values, which predict the variability explained by the model for new data, are in reasonable agreement with the Adjusted- $R^{2}$ values and in all three cases the Adeq. Precision tests, which measure the signal-to-noise ratio, are greater than 4 , which is the minimum value typically accepted for this term.

To evaluate model reliability further, four additional walls were built; their responses were then compared with those predicted by Stat-Ease

Design-Expert $\AA$ 7.1. TWW and EWW values were always within the $95 \%$ confidence interval; however two of the four measured LH values fell outside the $95 \%$ confidence interval. This confirms what has been discussed previously regarding the low reliability of the regression analysis for the LH response.

Contour plots were generated to represent graphically the regression equations. The EWW (Fig. 10) is maximised when the TS is minimised;

Table 3: Statistical tests performed on the final models.

\begin{tabular}{lccc}
\hline Statistical Test & TWW model & EWW model & LH model \\
\hline $\mathrm{R}^{2}$ & 0.9675 & 0.9540 & 0.9108 \\
Adjusted-R $^{2}$ & 0.9552 & 0.9393 & 0.8885 \\
Pred-R $^{2}$ & 0.9310 & 0.9228 & 0.8093 \\
Adeq. Precision & 32.026 & 29.052 & 22.471 \\
P-values & $<0.0001$ & $<0.0001$ & $<0.0001$ \\
\hline
\end{tabular}



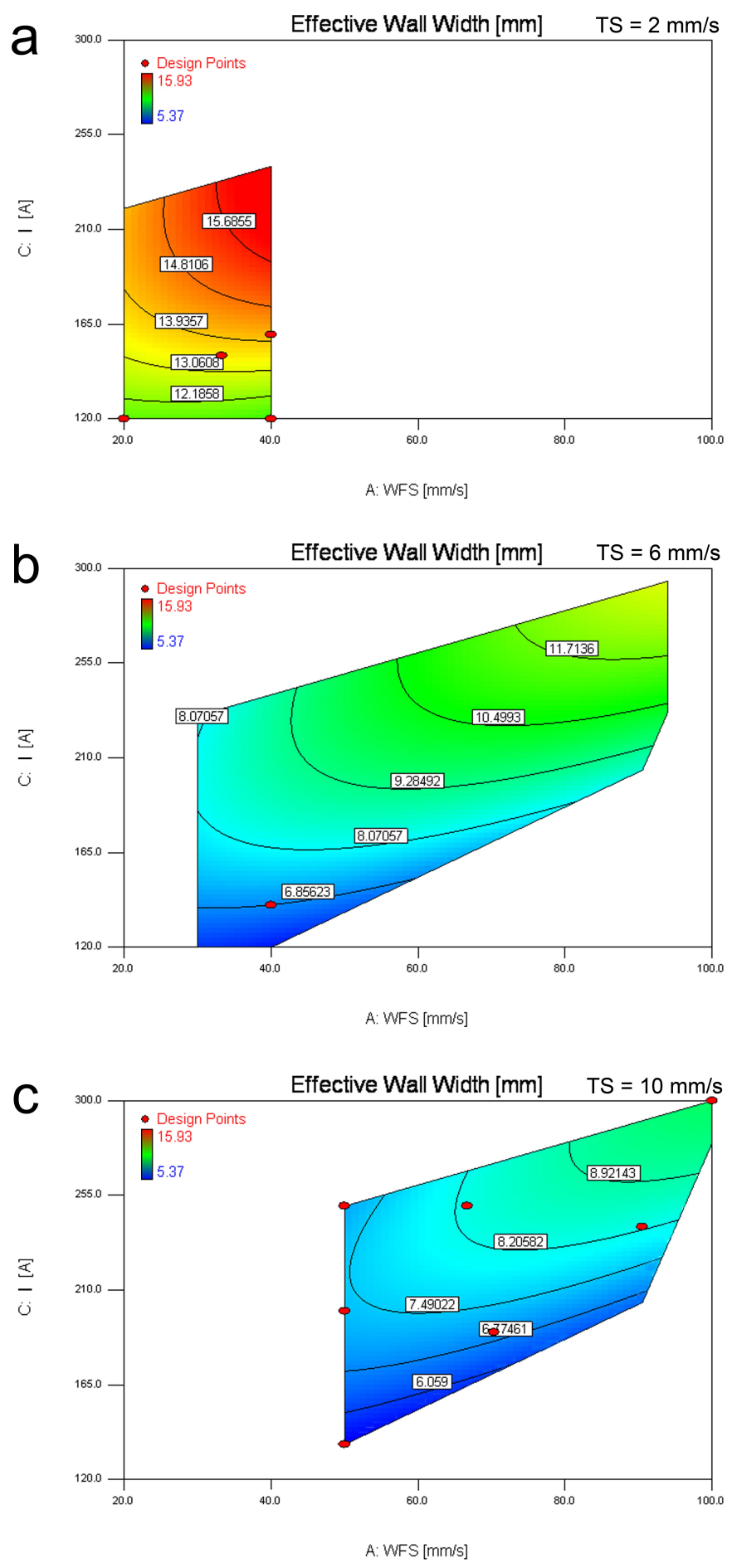

Figure 10: Effective Wall Width contour plots. (a) $\mathrm{TS}=2 \mathrm{~mm} / \mathrm{s}$; (b) $\mathrm{TS}=6$ $\mathrm{mm} / \mathrm{s}$; (c) $\mathrm{TS}=10 \mathrm{~mm} / \mathrm{s}$. 

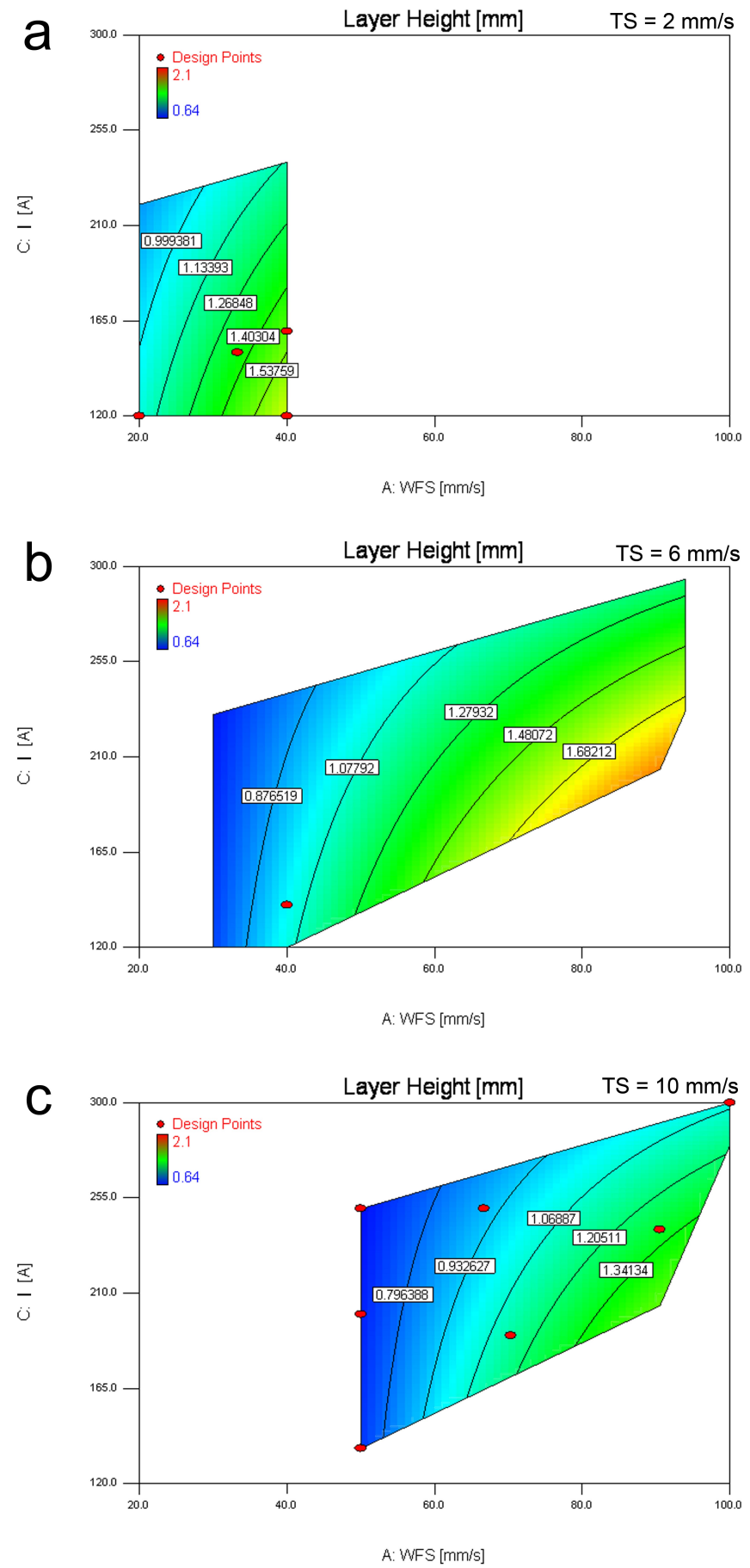

Figure 11: Layer Height contour plots. (a) $\mathrm{TS}=2 \mathrm{~mm} / \mathrm{s}$; (b) $\mathrm{TS}=6 \mathrm{~mm} / \mathrm{s}$; (c) $\mathrm{TS}=10 \mathrm{~mm} / \mathrm{s}$. 
the walls get thinner when the TS increases. The process has a behaviour similar to GMAW, in which Sequeira Almeida and Williams (2010) reported that the wall width depends on the WFS/TS ratio. In fact, the higher the ratio, the thicker the walls, as the amount of fed material per unit length increases. The Current also affects the EWW (Fig. 10), with larger values causing wider walls.

Note that the maximum TWW is achieved at virtually the same conditions as the maximum EWW $(\mathrm{WFS}=42 \mathrm{~mm} / \mathrm{s}, \mathrm{TS}=2 \mathrm{~mm} / \mathrm{s}$ and Current $=237$ A for the TWW vs. WFS $=41 \mathrm{~mm} / \mathrm{s}, \mathrm{TS}=2.1 \mathrm{~mm} / \mathrm{s}$ and Current $=240 \mathrm{~A}$ for the EWW) showing the strong correlation between the two responses. The LH results are shown in Fig. 11 which demonstrates a behaviour which is in contrast to the one described for TWW and EWW: LH increases as WFS increases and Current decreases. As noted previously, high currents cause spreading of the deposit, so lower currents which reduce the heat input enable the deposit to solidify earlier. Maximum LH is obtained with an intermediate travel speed at the following conditions: $\mathrm{WFS}=68 \mathrm{~mm} / \mathrm{s}, \mathrm{TS}=3.4 \mathrm{~mm} / \mathrm{s}$ and Current $=167 \mathrm{~A}$. An attempt to optimise the process could present the typical problems of multi-objective optimisation, which according to Trautmann and Mehnen (2009) aims at optimising concurrent objectives which are contradictory but depend on the same set of variables. Therefore, as reported by Ehrgott (2005), there is no unique optimal solution, but often a set of different solutions calculated by using desirability functions. In PWD, EWW is the first parameter that must be specified, as it represents the main design specification; WFS, to which the deposition rate depends on, should be maximised to build the walls as fast as possible, whenever productivity is a key factor. Most of the optimal solutions have a Desirability Index above 
0.90. The Desirability Index, which is the output of a desirability function, is equal to 1 when the response is at its target, or to 0 when the response is not acceptable (Montgomery, 2005). In some cases, it is possible to calculate solutions with Desirability Index=1, as when, given EWW=12 $\mathrm{mm}$, it follows WFS $=100 \mathrm{~mm} / \mathrm{s}$, Current=294 A and TS=7 mm/s.

\section{Conclusions}

In this paper it has been demonstrated:

- The feasibility of using Plasma Wire Deposition for ALM of large aerospace structural components;

- The process window for Plasma Wire Deposition, including a description of the parameters combination where deposition becomes unfeasible and the defects that are likely to occur outside those parameters ranges;

- Compared to competing Additive Layer Manufacturing processes, the Effective Wall Width and deposition rates are much higher. Nevertheless, the layer height was lower than with the GMAW-CMT process;

- The metallography shows a Widmanstätten microstructure within large columnar grains;

- Oxidation and distortion can be issues, particularly when the deposition occurs out-of-chamber;

- A statistical model that enabled the selection of process parameters to maximise the layer height and deposition rate for a given Effective Wall Width. 


\section{References}

Akula, S. and Karunakaran, K. P., 2006. Hybrid adaptive layer manufacturing: An Intelligent art of direct metal rapid tooling process. Robotics and Computer-Integrated Manufacturing. 22, 113-123.

Baufeld, B., Biest, O. V. d. and Gault, R., 2010. Additive manufacturing of $\mathrm{Ti}-6 \mathrm{Al}-4 \mathrm{~V}$ components by shaped metal deposition: Microstructure and mechanical properties. Materials and Design. 31, S106-S111.

Boyer, R., Welsch, G., Collings, E. W., 1994. Materials Properties Handbook - Titanium Alloys. ASM International.

Ehrgott, M., 2005. Multicriteria optimization, 2nd ed Springer, Berlin; New York.

Eze, E. (2009), VBC welding system parameter effect on the shape and microstructure of additively manufactured Ti6Al4V titanium alloy, Cranfield University.

Kelly, S. M. and Kampe, S. L., 2004a. Microstructural Evolution in Laser-Deposited Multilayer Ti-6Al-4V Builds: Part I. Microstructural Characterization. Metallurgical And Materials Transactions A-Physical Metallurgy And Materials Science. 35A(6), 1869-1879.

Kelly, S. M. and Kampe, S. L., 2004b. Microstructural Evolution in Laser-Deposited Multilayer Ti-6Al-4V Builds: Part II. Thermal Modeling. Metallurgical And Materials Transactions A-Physical Metallurgy And Materials Science. 35A(6), 1869-1879.

Kruth, J. P., Levy, G., Klocke, F. and Childs, T. H. C., 2007.

Consolidation phenomena in laser and powder-bed based layered manufacturing. CIRP Annals - Manufacturing Technology. 56, 730-759. Lütjering, G. and Williams, J.C., 2007. Titanium, 2nd ed Springer, Berlin; New York. 
Messler, R. W., 1999. Principles of welding: processes, physics, chemistry, and metallurgy. John Wiley, New York; Chichester.

Milewski, J. O., Dickerson, P. G., Nemec, R. B., Lewis, G. K. and Fonseca, J. C., 1999. Application of a manufacturing model for the optimization of additive processing of Inconel alloy 690. Journal of Materials Processing Technology. 91, 18-28.

Montgomery, D. C., 2005. Design and analysis of experiments, 6th ed Wiley, Hoboken; Great Britain.

Murr, L. E., Gaytan, S. M., Ceylan, A., Martinez, E., Martinez, J. L., Hernandez, D. H., Machado, B. I., Ramirez, D. A., Medina, F., Collins, S. and Wicker, R. B., 2010. Characterization of titanium aluminide alloy components fabricated by additive manufacturing using electron beam melting. Acta Materialia. 58, 1887-1894.

Roy, R., Azene, Y. T., Farrugia, D., Onisa, C. and Mehnen, J., 2009. Evolutionary multi-objective design optimisation with real life uncertainty and constraints. CIRP Annals - Manufacturing Technology. 58, 169-172. Sequeira Almeida, P.M. and Williams, S.W. (2010), "Innovative process model of $\mathrm{Ti}-6 \mathrm{Al}-4 \mathrm{~V}$ additive layer manufacturing using Cold Metal Transfer (CMT)", 21st International Solid Freeform Fabrication Symposium, August 9-11, 2010, Austin, Texas, USA. Tolochko, N. K., Mozzharov, S. E., Yadroitsev, I. A., Laoui, T., Froyen, L., Titov, V. I. and Ignatiev, M. B., 2004. Selective laser sintering and cladding of single-component metal powders. Rapid Prototyping Journal. $10(2), 88-97$.

Trautmann, H. and Mehnen, J., 2009. Preference-based Pareto optimization in certain and noisy environments. Engineering Optimization. 41, 23-38. 
Wang, F., Mei, J. and Wu, X., 2006. Microstructure study of direct laser fabricated Ti alloys using powder and wire. Applied Surface Science. 253, 1424-1430.

Weman, K., 2003. Welding processes handbook, Woodhead Publishing, Cambridge, Eng.

Xiong, X., 2008. A new method of direct metal prototyping: Hybrid plasma deposition and milling. Rapid Prototyping Journal. 14, 53-56. Zhang, H., Xu, J. and Wang, G., 2003. Fundamental study on plasma deposition manufacturing. Surface and Coatings Technology. 171, 112-118. 